\title{
Entropy - system approach to assess the ecological status of reservoirs in Armenia
}

\author{
Gevorg Simonyan and Gevorg Pirumyan
}

Yerevan State University , Alek Manoogian Street, 0025 Yerevan, Armenia

*Correspondence: sim-gev@mail.ru; gevorg.simonyan@ysu.am ;Tel.: (+374) 91-378-829.

Abstract: In this article, the quality of water in the reservoirs of Lake Arpi, Lake Yerevan, Akhuryan, Azat, Aparan and Kechut was estimated with usage of the Armenian Water Quality Index. It was established that in the waters of reservoirs the the maximum permissible concentration of copper, vanadium, aluminum, chromium, manganese, iron, $\mathrm{NH}_{4}{ }^{+}$and $\mathrm{NO}_{2}-$ regularly increases. The following computational algorithm was used for determination of the Armenian Water Quality Index values: determine the number of cases of MPC excess of $\mathrm{i}$-substance or indicator of water $-\mathrm{n}$; to estimate the total amount of cases of the maximum permissible concentration $(\mathrm{N})-\mathrm{N}=\sum \mathrm{n}$; to computes $\log _{2} \mathrm{~N}$, $\log _{2} \mathrm{n}$ and $\sum \mathrm{n} \log _{2} \mathrm{n}$; to determine geoecological syntropy (I) and entropy $(\mathrm{H}): \mathrm{I}=\sum n \log _{2 \mathrm{n}} / \mathrm{N}$ and $\mathrm{H}=\log _{2} \mathrm{~N}-\mathrm{I}$. Then, Geo-Ecological Evolving Organized index index was determined: $\mathrm{G}=\mathrm{H} / \mathrm{I}$. Further, the total amount multiplicity of MAC exceedances was estimated: (M) $-M=\sum m$ and $\log _{2} \mathrm{M}$ was computed. Finally, Armenian Water Quality Index was obtained: AWQI $=\mathrm{G}+$ $0.1 \log _{2} \mathrm{M}$. It was established that the Armenian Water Qquality Index showed a linear dependence on the Water Contamination Index, the Specific Combinatory Water Quality Index, the Geo-Ecological Evolving Organized index and an inverse dependence on the Canadian Water Quality Index.

Keywords: reservoir, water quality indexes, GEVORG index, Armenian Water Quality Index, Armenia

\section{Introduction}

The study of ecological status of the reservoir in Armenia is important for evaluation of their water quality, as well as for their further rational use. Water resources play a vital role in various sectors of economy such as industrial activities, agriculture, forestry, fisheries, hydropower generation and other creative activities[1]. The suitability of water sources for human consumption has been described in terms of Water Quality Index (WQI), which one of the most effective ways to describe the quality of water. WQI utilizes the water quality data and helps in the modification of the policies, which are formulated by various environmental monitoring agencies. The WQI is a mathematical instrument used to transform large quantities of water quality data into a single number and which improves the understanding of water quality issues. This is done by integrating relevant water quality data and generating a score that describes water quality status and can be also used to evaluate water quality trends [2].

Water quality of any specific area or specific source can be assessed by using physical, chemical and biological parameters. The values of these parameters are harmful for human health if they occurre more than defined limits.

Different WQI have been developed worldwide which are greatly differing in terms of mathematical structures, the numbers and types of variables included, etc.

Currently, hydrological practice actively uses several dozen [3-14]. It must be noted that most developing complex characteristics of water object in any methodology is connected with the existing maximum permissible concentration (MPC) $[1,15,16]$.

WQI was first developed by Horton (Horton, 1965) [3] in the United States, selecting the 10 most frequently used water quality variables, such as dissolved oxygen (DO), $\mathrm{pH}$, coliform, conductivity, alkalinity, and chloride, etc., and widely used and accepted in European, African and Asian countries. Horton placed grading scales and weights for determining factors to give the relative importance of each parameter in water quality. Furthermore, a new WQI similar to Horton's index has also been developed by the group of Brown in 1970 [4], which was based on weights of individual parameters. Recently, many modifications have been considered for WQI concept through various scientists and experts. Canadian Council of Ministers of the Environment has developed WQI - Canadian Water Quality Index (CWQI), which can be applied by 
numerous water agencies in various countries with slight modification [5]. In 1995, the Canadian Ministry of the Environment developed the British Columbia Water Quality Index [6]. The Oregon Water Quality Index takes into account eight water quality variables (temperature, $\mathrm{DO}, \mathrm{pH}, \mathrm{BOD}$, total phosphorus, total solids, fecal E. coli, ammonia, and nitrate nitrogen). For selection of variables, the Delphi method was used[7]. Malaysia Water Quality Index developed by the Department of the Environment of Malaysia-and successfully applied evaluation water quality of 462 rivers in Malaysia. The calculation has included six water parameters: DO, BOD, COD, ammonia nitrogen, suspended solids and $\mathrm{pH}$ [7]. The Bascarn Water Quality Index was developed by Bascarón (1979) specifically for Spain [8]. In 1976, the Scottish Engineering Department improved and developed the Scottish Water Quality Index[9]. An effective gradation index for diagnosing a generalized river quality has been developed and illustrated for study of the Keya River in Taiwan[10]. The Universal Water Quality Index for Turkey was developed by Boyacioglu [11] based on water quality standards set by the Council of European Communities. Sargaonkar and Deshpande [12] developed Overall Index of Pollution for Indian rivers based on measurements and subsequent classification of $\mathrm{pH}$, turbidity, dissolved oxygen, BOD, hardness, total dissolved solids, total coliforms, arsenic, and fluoride.

As a result of anthropogenic pollution of the aquatic environment, the entropy of the system changes, which is not always taken into account in hydrochemical studies. For assessing the quality of surface water and environmental pollution, we recently propose the entropy Geo-Ecological Evolving Organized Index (GEVORG) (G) and the Armenian Water Quality Index (AWQI) [17-19]

The purpose of this article is to assess the water quality of the reservoirs of Lake Arpi, Lake Yerevan, Akhurian, Azat, Aparan and Kechut by using the Armenian Water Quality Index.

\section{Materials and Methods}

\subsection{Study area}

About 74 reservoirs with total volume of 988 million $\mathrm{m}^{3}$ are concentrated today in Armenia [20,21]. The largest reservoir in the territory of Armenia is Akhuryan Reservoir with a volume of 525 million $\mathrm{m}^{3}$. The volume and spilway height of reservoirs are shown in Table 1.

Table 1. The volume and spilway heighr for reservoirs

\begin{tabular}{cccc}
\hline Name of reservoir & Region & Volume $\left(\right.$ per million $\left.\mathbf{m}^{3}\right)$ & Spillway Height $\mathbf{( m )}$ \\
\hline Akhuryan & Shirak & 525 & 59.1 \\
Lake Arpi & Shirak & 105 & 15 \\
Aparan & Aragatsotn & 91 & 52.6 \\
Azat & Ararat & 70 & 76 \\
Kechut & Syunik & 23 & 20 \\
Lake Yerevan & Yerevan & 5 & 18
\end{tabular}

Akhuryan Reservoir is a reservoir on the Akhuryan River between Armenia and Turkey. The reservoir has a surface area of $54 \mathrm{~km}^{2}$, max long $20 \mathrm{~km}$. It is one of the largest reservoirs in the Caucasus. Coordinates $40^{\circ} 33^{\prime} 47.67^{\prime \prime} \mathrm{N} 43^{\circ} 39^{\prime} 16.26^{\prime \prime} \mathrm{E}$. Lake Arpi is situated in the north-west of the Republic of Armenia. The lake is fed by meltwater and four streams, and it is the source of the Akhuryan River. Being alpine specific ecosystem with its rare flora and fauna it ensures ecological balance of adjacent extensive area. The reservoir-lake spans $7.3 \mathrm{~km}$ long and $4.3 \mathrm{~km}$ wide, with an area of $20 \mathrm{~km}^{2}$. Coordinates $41^{\circ} 03^{\prime} 0^{\prime \prime} \mathrm{N} 43^{\circ} 37^{\prime} 00^{\prime \prime} \mathrm{E}$. Yerevan Lake is an artificial reservoir located in the capital of Armenia in Yerevan. The reservoir-lake Yerevan spans 7.3km long and $5.0 \mathrm{~km}$ wide, with an area of $0.65 \mathrm{~km}^{2}$. Coordinates $40^{\circ} 9^{\prime} 35.04^{\prime \prime} \mathrm{N} 44{ }^{\circ} 28^{\prime} 36.54 " \mathrm{E}$. Aparan Reservoir is a reservoir in Armenia, in the Aragatsotn region. It is built on the river Kassah with area of $7.9 \mathrm{~km}^{2}$. Used for

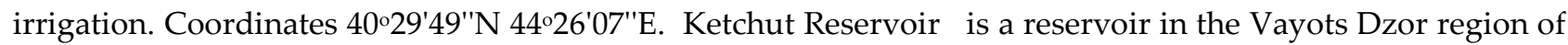
Armenia, on the river Arpa, $3.5 \mathrm{~km}$ south of the resort town of Jermuk. The reservoir was built in 1981. Water from it through the conduit enters Lake Sevan to regulate the level. Coordinates 39॰47'54"N 4539'22"E. Azat Reservoir is a reservoir located in Armenia, in the Ararat region, above the village of Lanjazat, at an altitude of $1050 \mathrm{~m}$ above sea level. The reservoir was built on the Azat River. The volume of the lake is 70 million $\mathrm{m}^{3}$. Water is used tfor irrigateion the Ararat Plain. Coordinates 40॰04'00"N 4436'00"E. 


\subsection{Indexes determination procedure}

\subsubsection{Canadian council of ministers of the environment water quality index (CWQI)}

CWQI provides a consistent method, which have been formulated by Canadian jurisdictions for conveying water quality information for both management and public [5]. Moreover, a committee established under the Canadian Council of Ministers of the Environment WQI, which can be applied by numerous water agencies in various countries with slight modification. This method has been developed to evaluate surface water for protection of aquatic life in accordance to specific guidelines. The parameters related with various measurements may vary from one station to the other and sampling protocol requires at least four parameters, sampled at least four times. The calculation of index scores in CWQI method can be obtained by using the following relation:

$$
C W Q I=100-\frac{\sqrt{F_{1}^{2}+F_{2}^{2}+F_{3}^{2}}}{1.732}
$$

where scope $\left(F_{1}\right)$ is the number of variables, which objectives don't meet, $F_{1}=$ [№ of failed variables/total no? of variables] $\times 100$; frequency $\left(F_{2}\right)$ - the number of times by which the objectives don't meet, $F_{2}=$ [№ of failed tests/total № of tests] $\times 100$; amplitude $\left(F_{3}\right)$ - the amount by which the objectives don't meet.

(a) The number of times by which an individual concentration is greater than (or less than, when the objective is a minimum) the objective is termed an "excursion" and is expressed as follows. When the test value must not exceed the objective:

$$
\text { excursion }_{i}=[\text { Failed test valuei } / \text { Objectivej }]-1
$$

(b) The collective amount by which individual tests are out of compliance is calculated by summing the excursions of individual tests from their objectives and dividing by the total number of tests (both those meeting objectives and those not meeting objectives). This variable, referred to as the normalized sum of excursions, or nse, is calculated as:

normalized sum of excursions (nse) $=\sum_{i=1}^{n}$ excursions $_{i}$ / № of tests

(c) $F_{3}=[$ nse $/ 0.01$ nse +0.01$]$

Therefore, five categories have been suggested for classification the water qualities which are summarized in Table 2.

Table 2. Classes of water quality depending on the value of CWQI

\begin{tabular}{ccc}
\hline CWQI value & Rating of water quality & Water quality classes \\
\hline $95-100$ & excellent water quality & 1 \\
$80-94$ & good water quality & 2 \\
$60-79$ & fair water quality & 3 \\
$45-59$ & marginal water quality & 4 \\
$0-44$ & poor water quality & 5 \\
\hline
\end{tabular}

\subsubsection{Water contamination index (WCI)}

WCI was established by the USSR Goskomgidromet (State Committee of Hydrometeorology) [13] and belongs to the category of indicators most often used to assess the quality of water bodies. This index is a typical additive coefficient and represents the average percentage of exceeding the MPC for a strictly limited number of individual ingredients:

$$
W C I=\frac{1}{n} \sum_{i=1}^{n} \frac{C_{i}}{M P C_{i}}
$$

where: $C_{i}$ is the concentration of the component (in some cases - the value of the physicochemical parameter); $n$ - the number of indicators used for calculateion the index, $n=6(\mathrm{pH}$, biological oxygen demand of $\mathrm{BOD}_{5}$ dissolved oxygen in water, petroleum products, nitrite ions $\left(\mathrm{NO}_{2}{ }^{-}\right)$, and ammonium ion 
$\left(\mathrm{NH}_{4}^{+}\right)$). Seven categories have been proposed for the classification of water quality, which are listed in Table 3 .

Table 3. Classes of water quality depending on the value of WCI

\begin{tabular}{ccc}
\hline WCI value & Rating of water quality & Water quality classes \\
\hline up to 0,2 & very clean & I \\
$0.2-1.0$ & clean & II \\
$1.0-2.0$ & moderately polluted & III \\
$2.0-4.0$ & contaminated & IV \\
$4.0-6.0$ & dirty & V \\
$6.0-10.0$ & very dirty & VI \\
$>10.0$ & extremely dirty & VII \\
\hline
\end{tabular}

\subsubsection{Specific combinatory water quality index (SCWQI)}

In accordance with RD 52.24.643-2002, 'The method for the integrated assessment of the degree of contamination of surface waters by hydrochemical indicators' the calculation of the specific combinatorial water quality index has been introduced [14] . To assess the quality of water in rivers and water bodies, it is divided into several classes contamination. The classes are based on the intervals of the specific combinatory water pollution index, depending on the number of critical pollution indicators. At least 15 indicators are analyzed. Required list includes: dissolved oxygen in water, BOD5, chemical oxygen consumption - COD, phenols, petroleum products, nitrite ions $\left(\mathrm{NO}_{2}^{-}\right)$, nitrate ions $\left(\mathrm{NO}_{3}^{-}\right)$ammonium ion $\left(\mathrm{NH}_{4}^{+}\right)$, iron total $\left(\mathrm{Fe}^{2+}\right.$ and $\left.\mathrm{Fe}^{3+}\right)$, copper $\left(\mathrm{Cu}^{2+}\right)$, zinc $\left(\mathrm{Zn}^{2+}\right)$, nickel $\left(\mathrm{Ni}^{2+}\right)$, manganese $\left(\mathrm{Mn}^{2+}\right)$, chlorides and sulphates. The value of SCWQI is determined by the frequency and the multiplicity of the MPC exceeding by several indicators and can vary in waters of different degree of contamination from 1 to 16 (for pure water is 0 ). The highest index value corresponds to the worst water quality. Taking into account the number of bullpen, it is allows to divide the surface waters into 5 classes, depending on the degree of their contamination. The 3rd and 4 th classes for a more detailed water quality assessment are divided into 2 and 4 categories, respectively. The classification of water quality is given in Table 4 .

Table 4. Surface water quality categories

\begin{tabular}{|c|c|c|c|c|c|c|c|}
\hline \multirow{3}{*}{ Class and rank } & \multirow{3}{*}{$\begin{array}{c}\text { Characteristics of } \\
\text { the state of water } \\
\text { pollution }\end{array}$} & \multicolumn{6}{|c|}{ Specific combinatorial index of water pollution } \\
\hline & & \multirow{2}{*}{$\begin{array}{c}\text { without } \\
\text { regard to } \\
\text { the } \\
\text { number of } \\
\text { bullpen }\end{array}$} & \multicolumn{5}{|c|}{ depending on the number of accountable bullpen } \\
\hline & & & 1 & 2 & 3 & 4 & 5 \\
\hline 1 st & $\begin{array}{l}\text { conditionally } \\
\text { pure }\end{array}$ & 1 & 0.9 & 0.8 & 0.7 & 0.6 & 0.5 \\
\hline 2 nd & $\begin{array}{l}\text { slightly } \\
\text { contaminated }\end{array}$ & 12 & $0.9-1.8$ & $0.8-1.6$ & $0.7-1.4$ & $0.6-1.2$ & $0.5-1.0$ \\
\hline 3rd & contaminated & $2-4$ & $1.8-3.6$ & $1.6-3.2$ & $1.4-2.8$ & $1,2-2,4$ & $1.0-2.0$ \\
\hline discharge 'a' & contaminated & $2-3$ & $1.8-2.7$ & $1.6-2.4$ & $1.4-2.1$ & $1,2-1,8$ & $1.0-1.5$ \\
\hline Rank 'b' & very polluted & $3-4$ & $2.7-3.6$ & 2.4-3.2 & $2.1-2.8$ & $1.8-2.4$ & $1.5-2.0$ \\
\hline 4 th & dirty & $4-11$ & $3.6-9.9$ & $3.2-8.8$ & $2.8-7.7$ & $2.4-6.6$ & $2.0-5.5$ \\
\hline discharge 'a' & dirty & $4-6$ & $3.6-5.4$ & $3.2-4.8$ & $2.8-4.2$ & $2.4-3.6$ & $2.0-3.0$ \\
\hline Rank 'b' & dirty & $6-8$ & $5.4-7.2$ & $4.8-6.4$ & $4.2-5.6$ & $3.6-4.8$ & $3.0-4.0$ \\
\hline Rank 'B' & very dirty & $8-10$ & $7.2-9.0$ & $6.4-8.0$ & $5.6-7.0$ & $4.8-6.0$ & $4.0-5.0$ \\
\hline Grade 'g' & very dirty & $8-11$ & $9.0-9.9$ & $8.0-8.8$ & $7.0-7.7$ & $6.0-6.6$ & $5.0-5.5$ \\
\hline 5 th & extremely dirty & $\begin{array}{l}11 \text { and } \\
\text { more }\end{array}$ & 9.9 and more & $\begin{array}{c}8,8 \text { and } \\
\text { more }\end{array}$ & $\begin{array}{c}7.7 \text { and } \\
\text { more }\end{array}$ & $\begin{array}{l}6.6 \text { and } \\
\text { more }\end{array}$ & $\begin{array}{c}5,5 \text { and } \\
\text { more }\end{array}$ \\
\hline
\end{tabular}




\subsubsection{Geo-Ecological Evolving Organized index and Armenian index of water quality.}

An open system can exchange energy, material and, which is not less important, information with environment. The system consumes information from the environment and provides information to environment for acting and interacting with environment. Shannon $[22,23]$ was the first who related concepts of entropy and information. He has suggested that entropy is the amount of information attributable to one basic message source, generating statistically independent reports. Get any amount of information entropy is equal to the lost. Information entropy for independent random event $x$ with $N$ possible states is calculated by the following equation:

$$
\mathrm{H}=-\sum_{\mathrm{i}=1}^{\mathrm{N}} \mathrm{p}_{\mathrm{i}} \log _{2} \mathrm{p}_{\mathrm{i}}
$$

where $P_{i}$ is the probability of frequency of occurrence of an event.

Different processes in hydroecological systems can occur both with increasing and decreasing of entropy. Pollution of water systems can be represented as a system of the hydro-chemical parameters (elements), the concentration of which exceeds the MPC. Then, in the equation Shannon $P_{i-}$ probability of the number of cases of MPC excess of $i$-substance or water indicator of total cases of MPC - N, $P_{i}=n_{i} / N$.

For determineation the values of the GEVORG index and Armenian index of environmental quality, the following computational algorithm is used[17-19]:

1. To determine the number of cases of MPC excess of i-substance or indicator of water $-n$.

2. To estimate the total amount of cases at the maximum permissible concentration $(\mathrm{N})-N=\sum n$.

3. To compute $\log _{2} N, n \log _{2} n$ and $\sum n \log _{2} n$.

4. To determine geoecological syntropy $(I)$ and entropy $(H)$ :

$$
I=\sum n \log _{2} n / N \text { and } H=\log _{2} N-I \text {. }
$$

5. Then GEVORG index $(\mathrm{G})$ is determined: $\mathrm{G}=H / \mathrm{I}$.

6. Further, the total amount multiplicity of MPC exceedances is estimated: $(\mathrm{M})-\mathrm{M}=\sum \mathrm{m}$.

7. After $\log _{2} \mathrm{M}$ is computesd.

8. Finally, Armenian water quality index is obtained: $A W Q I=G+0.1 \log _{2} \mathrm{M}$.

Therefore, five categories have been suggested for classification the water qualities which are summarised in Table 5.

Table 5. Classes of water quality depending on the value of GEWORG and AWQI

\begin{tabular}{cccc}
\hline GEVORG value & AWQI value & Rating of water quality & Water quality classes \\
\hline$<0.7$ & $<1.1$ & excellent water quality & 1 \\
$0.7-1.0$ & $1,1-1,4$ & good water quality & 2 \\
$1.0-1.4$ & $1.4-1.8$ & fair water quality & 3 \\
$1.4-1.7$ & $1.8-2.1$ & marginal water quality & 4 \\
$>1.7$ & $>2.1$ & poor water quality & 5 \\
\hline
\end{tabular}

\section{Results and discussion}

\subsection{Reservoirs Lake Arpi, Akhuryan and Lake Yerevan}

It was established in the waters of rezervoirs Lake Arpi, Lake Yerevan and Akhuryan MPC of nitrite ions, ammonium ion, copper, vanadium, aluminum, chrom, manganese and iron was regularly increased [24]. For example, in rezervoir Lake Arpi number of MPC increasing cases for $\mathrm{Al}, \mathrm{V}, \mathrm{Cu}, \mathrm{Mn}, \mathrm{Fe}$ and have been changed 6, 6, 6, 5, 4 and 2 times, respectively. The amount of excess cases of MPC $-N=20, \sum n \log _{2} n=47.9, I$ $=47.9 / 20=2.395, \quad H=\log _{2} 20-2.395=4.319-2.395=1.924$, GEVORG $=G=1.924 / 2.395=0.8035$. The total amount of the multiplicity of MPC exceedances $-\mathrm{M}=\sum \mathrm{m}=13.2, \log _{2} \mathrm{M}=3.72$, GEVORG $=0.8035+0.372=$ 1.1755. The values of the GEVORG and AWQI indexes are given in Table 6.

Table 6. Values of GEVORG and AWQ I indexes for reservoirs Lake Arpi, Akhuryan and Lake 


\begin{tabular}{|c|c|c|c|c|c|c|}
\hline \multirow{3}{*}{$\begin{array}{l}\text { Reservoir } \\
\text { Positions } \\
\text { Indicator }\end{array}$} & \multicolumn{2}{|c|}{ Lake Arpi } & \multicolumn{2}{|c|}{ Akhuryan } & \multicolumn{2}{|c|}{ Lake Yerevan } \\
\hline & \multicolumn{2}{|c|}{109} & \multicolumn{2}{|c|}{110} & \multicolumn{2}{|r|}{112} \\
\hline & $n$ & $n \log _{2} n$ & $n$ & $n \log _{2} n$ & $n$ & $n \log _{2} n$ \\
\hline $\mathrm{NO}_{2}^{-}$ & 0 & 0 & 4 & 8 & 12 & 43.0 \\
\hline $\mathrm{NH}_{4}{ }^{+}$ & 0 & 0 & 0 & 0 & 10 & 33.2 \\
\hline $\mathrm{DOD}_{5}$ & 0 & 0 & 0 & 0 & 6 & 15.5 \\
\hline $\mathrm{Al}$ & 6 & 15.5 & 3 & 4.75 & 7 & 19.64 \\
\hline $\mathrm{V}$ & 6 & 15.5 & 7 & 19.64 & 12 & 43.0 \\
\hline $\mathrm{Cu}$ & 6 & 15.5 & 6 & 15.5 & 10 & 33.2 \\
\hline $\mathrm{Mn}$ & 5 & 11.6 & 0 & 0 & 0 & 0 \\
\hline $\mathrm{Fe}$ & 4 & 8 & 0 & 0 & 0 & 0 \\
\hline $\mathrm{Cr}$ & 2 & 2 & 0 & 0 & 0 & 0 \\
\hline Se & 0 & 0 & 0 & 0 & 6 & 15.5 \\
\hline $\mathrm{N}$ & \multicolumn{2}{|c|}{29} & \multicolumn{2}{|c|}{20} & \multicolumn{2}{|r|}{63} \\
\hline$\sum \mathrm{nlog}_{2} \mathrm{n}$ & \multicolumn{2}{|c|}{68.1} & \multicolumn{2}{|c|}{47.9} & \multicolumn{2}{|r|}{203.04} \\
\hline I & \multicolumn{2}{|c|}{2.348} & \multicolumn{2}{|c|}{2.395} & \multicolumn{2}{|r|}{3,22} \\
\hline $\mathrm{H}$ & \multicolumn{2}{|c|}{2.507} & \multicolumn{2}{|c|}{1.924} & \multicolumn{2}{|r|}{2.75} \\
\hline GEVORG & \multicolumn{2}{|c|}{1.068} & \multicolumn{2}{|c|}{0.8035} & \multicolumn{2}{|r|}{0.855} \\
\hline $\mathrm{M}=\Sigma \mathrm{m}$ & \multicolumn{2}{|c|}{35.5} & \multicolumn{2}{|c|}{13.2} & \multicolumn{2}{|r|}{36.3} \\
\hline $\log _{2} \mathrm{M}$ & \multicolumn{2}{|c|}{5.14} & \multicolumn{2}{|c|}{3.72} & \multicolumn{2}{|r|}{5.180} \\
\hline AWQI & \multicolumn{2}{|c|}{1.5826} & \multicolumn{2}{|c|}{1.1755} & \multicolumn{2}{|r|}{1.373} \\
\hline
\end{tabular}

\subsection{Reservoirs Aparan, Azat and Kechut}

It was established in the waters of reservoirs Aparan, Azat and Kechut MPC of copper, vanadium and aluminum was increased regularly [24]. Calculations and values of the GEVORG and AWQI indexes for above mentioned reservoirs are given in Table 7.

Table 7. Values of GEVORG and AWQ I indexes for reservoirs Aparan, Azat and Lake Kechut

\begin{tabular}{|c|c|c|c|c|c|c|}
\hline \multirow{3}{*}{$\begin{array}{l}\text { Reservoir } \\
\text { Positions } \\
\text { Indicator }\end{array}$} & \multicolumn{2}{|r|}{ Aparan } & \multicolumn{2}{|r|}{ Azat } & \multicolumn{2}{|c|}{ Kechut } \\
\hline & \multicolumn{2}{|r|}{111} & \multicolumn{2}{|r|}{113} & \multicolumn{2}{|r|}{114} \\
\hline & $n$ & $n \log _{2} n$ & $n$ & $n \log _{2} n$ & $n$ & $n \log _{2} n$ \\
\hline $\mathrm{NO}_{2}^{-}$ & 1 & 0 & 0 & 0 & 0 & 0 \\
\hline $\mathrm{Al}$ & 4 & 8 & 2 & 2 & 10 & 33.2 \\
\hline $\mathrm{V}$ & 5 & 11.6 & 7 & 19.64 & 10 & 33.2 \\
\hline $\mathrm{Cu}$ & 0 & 0 & 2 & 2 & 0 & 0 \\
\hline $\mathrm{N}$ & \multicolumn{2}{|r|}{10} & \multicolumn{2}{|r|}{11} & \multicolumn{2}{|r|}{20} \\
\hline$\sum \log _{2} n$ & \multicolumn{2}{|r|}{19.6} & \multicolumn{2}{|r|}{23.64} & \multicolumn{2}{|r|}{66.4} \\
\hline I & \multicolumn{2}{|r|}{1.96} & \multicolumn{2}{|r|}{2.15} & \multicolumn{2}{|r|}{3.32} \\
\hline $\mathrm{H}$ & \multicolumn{2}{|r|}{1.36} & \multicolumn{2}{|r|}{1.31} & \multicolumn{2}{|r|}{1.0} \\
\hline GEVORG & \multicolumn{2}{|r|}{0.693} & \multicolumn{2}{|r|}{0.608} & \multicolumn{2}{|r|}{0.301} \\
\hline$M=\Sigma m$ & \multicolumn{2}{|r|}{7.2} & \multicolumn{2}{|r|}{11.7} & \multicolumn{2}{|r|}{6.7} \\
\hline $\log _{2} \mathrm{M}$ & \multicolumn{2}{|r|}{2.846} & \multicolumn{2}{|r|}{3.546} & \multicolumn{2}{|r|}{2.742} \\
\hline AWQI & \multicolumn{2}{|r|}{0.978} & \multicolumn{2}{|r|}{0.963} & \multicolumn{2}{|r|}{0.575} \\
\hline
\end{tabular}

The quality of waters of reservoirs Lake Arpi, Lake Yerevan, Akhuryan, Azat, Aparan and Kechut comprehensively was also evaluated by other indexes: WCI, CWQI, SCWQI. Values of the WQI indexes are given in Table 8. 
Table 8. Values of WQI for the reservoirs

\begin{tabular}{cccccr}
\hline Index & AWQI & GEVORG & WCI & CWQI & SCWQI \\
\hline Lake Arpi & 1.5826 & 1.068 & 2.11 & 69.29 & 2.04 \\
Lak Yerevan & 1.373 & 0.855 & 5.11 & 53.8 & 3.49 \\
Akhuryan & 1.1755 & 0.8035 & 2.24 & 72.84 & 2.09 \\
Aparan & 0.978 & 0.693 & 1.18 & 78.55 & 1.56 \\
Azat & 0.963 & 0.608 & 1.94 & 81.87 & 1.42 \\
Kełchut & 0.575 & 0.301 & 1.22 & 80.68 & 1.9 \\
\hline
\end{tabular}

According to WQI values, the water quality in the reservoirs Aparan, Azat- and Kechutis good and varieties between the 1st excellent class and the 2nd; good grade. The water quality of the reservoirs -Akhuryan, Lake Arpi and Lake Yerevan, on the contrary, is poor and varieties between 3rd 2nd poor classes, and restricts the use of water for irrigation purposes. Poor water quality of the Lake Arpi reservoir is associated with an increase in the amount of metals. Reduced water quality of the Akhuryan reservoir and Lake Yerevan is associated with pollution of municipal wastewaters in the river basin, respectively, in Gyumri and Yerevan. As a result of pollution by domestic wastewaters, the content of nitrite and ammonium nitrogen, BOD5 in increases river water and it has an oxygen deficiency.

With the help of the computer program 'Origin- 6 ' the analysis of the linear relationship between AWQI and other WQI - was provide: $\mathrm{AWQI}=a+b(\mathrm{WQI})$.

$$
\begin{gathered}
\text { AWQI }=(0,797 \pm 0,268)+(0,136 \pm 0,101) W C I ; R^{2}=0,55911 ; N=6 ; \\
\text { AWQI }=(0,635 \pm 0,461)+(0,226 \pm 0,210) \text { SCWQI; } R^{2}=0,47329 ; N=6 ; \\
\text { AWQI = }(0,139 \pm 0,092)+(1.342 \pm 0,121) \text { GEVORG; } R^{2}=0,984100 ; N=6 ; \\
\text { AWQI = }(2.825 \pm 0.881)-(0.024 \pm 0,012) \text { CWQI; } R^{2}=0,70105 ; N=6 .
\end{gathered}
$$

Thus, a correlation between AWQI and other WQI was established. Analysis of obtained data indicates that AWQI has liner dependence on WCI, SCWQI, GEVORG and an inverse dependence on CWQI. This results based on the fact that the scale of the Canadian index of quality of water begins from 100, and scales of indexes of impurity of water, an GEVORG, WQI and SCWQI start from scratch.

\section{Conclusions}

For the first time, the water quality in the reservoirs of Lakes Arpi, Yerevan, Akhuryan, Azat, Aparan and Kechuta was evaluated using the Armenian water quality index.

The water quality in the reservoirs Akhuryan, Lake Arpi and Lake Yerevan is poor, which is explained by the regular increasing of MPC of nitrite ions, ammonium ions, copper, vanadium, aluminum, chromium, manganese and iron.

It have been found that the Armenian water quality index is linearly dependent on the Water contamination index, the Specific combinatorial water quality index, the Geo-ecological evolving organized index, and has inverse relationship to the Canadian water quality index.

Author Contributions: G.S. and G.P. conceived and spent calculations; G.S. wrote the paper; G.P. reviewed the paper.

Conflicts of Interest: The authors declare no conflict of interest

\section{References}

1. Nikanorov, A.M. Scientific Basis for Water Quality Monitoring; Gidrometeoizdat, Sankt-Peterburg, Rossia, 2005, 577 p. (in Russian).

2. Stambuk-Giljanovic,N. Comparison of Dalmatian water evaluation indices. Water Environment Research 2003, 75 (5), 388-405.

3. Horton, R.K. An Index Number System for Rating Water Quality. J Water Poll Control Fed.1965, 37(3), 300 . 
4. Brown, R.M.; Mclennald, N. I.; Deininger, R.A.; Tozer, R.G. A Water Quality Index: Do We Dare? Water and Seawage Works, 1970, 117 (10), 339.

5. Canadian Council of Ministers of the Environment. 2001. Canadian water quality guidelines for the protection of aquatic life: CCME Water Quality Index 1.0, User's Manual. In: Canadian environmental quality guidelines, 1999, Canadian Council of Ministers of the Environment, Winnipeg.

6. Zandbergen, P.A.; Hall K.J. Analysis of the British Columbia Water Quality Index for watershed managers: A case study of two small watersheds. Water Quality Research Journal of Canada 1998, 33(4), 519-549.

7. Zulkifli, A.R. Water quality management in Malaysia.: Department of Environment Malaysia,2000, 35p.

8. Bascaron, M. Establishment of a methodology for the determination of water quality. Boletin Informativo del Medio Ambiente,1979, 9, 30-51.

9. SRDD, Scottish Research Development Department. Development of a water quality index. Applied Research \& Development, Report Number ARD3, Engineering Division, Edinburg, UK, 1976, 61p.

10. Liou, S.; Lo, S.; Wang,S. A generalized water quality index for Taiwan. Environmental Monitoring and Assessment, 2004, 96(1), 35-52.

11. Boyacioglu, H. Development of a water quality index based on a European classification scheme. Water $S A, 2013,33$ (1), 101-106.

12. Sargaonkar,A. ; Deshpand, V. Development of an Overall Index of Pollution for Surface Water Based on a General Classification Scheme in Indian Context, Environmental Monitoring and Assessment, 2003, 89(1),43-67.

13. Temporary guidelines of complex evaluation of surface and sea water quality by hydrochemical indicators have been introduced by the instruction of the State Committee of Hydrometeorology, No 250-1163, 1986, 5 p. (in Russian).

14. RD 52.24.643-2002. The Leading Document. Methodical Instructions. A Method of a Complex Assessment of Degree of Impurity of Surface Water on Hydrochemical Indicators. Gidrometeoizdat, Sankt-Peterburg: 2002. 55 p. (in Russian).

15. Tirkey,P.; Bhattacharya,T.; Chakraborty, S. Water Quality Indices- Important Tools for Water Quality Assessment. A. International Journal of Advances in Chemistry (IJAC), 2015, 1 (1), 15-29.

16. Maximum Permissible Concentrations of Harmful Substances in the Water. of Sanitary Water Bodies and the Requirements for the Composition and Properties of Water in Reservoirs at Points of Drinking and Cultural and Domestic Water Use. Ministry of Health of the USSR, HMC, Moscow, 1973, 14 p. (in Russian).

17. Simonyan, A.G.; Simonyan,G.S.; Pirumyan,G.P. Analysis of Environmental Status of the Rivers Aghstev and Getik with Armenian Index of Water Quality. European Journal of Natural History, 2016, 4, $22-27$.

18. Pirumyan, G.; Pirumyan, E.; Simonyan,G.; Simonyan,A. Method of determining the level of water pollution. RA Patent, №3063A, 2016 (in Armenian).

19. Simonyan, G.S.,;Simonyan, A. G.; Pirumyan, G. P. Systemic-entropy approach for estimating the water quality of a river. Oxidation Communications .2018, 41(2), 307-317.

20. Chilingaryan, L.A.; Mnatsakanyan, B .P.; Aghababyan, K.A.; Tokmajyan, H.V. Watercourse of Armenian rivers and lakes, Agropress, Yerevan, Armenia, 2002, 50 p. (in Armenian).

21. Dictionary of Physical-Geographic Objects in the Republic of Armenia. State Committee of the Real Estate Cadastre.Yerevan, Armenia, 2007. 136 p. (in Armenian).

22. Shannon,C. Works on Information Theory and Cybernetics. IL, Moscow, 1963, 830 p. (in Russian).

23. Shannon, C. E. A Mathematical Theory of Communication. The Bell System Technical Journal, 1948, 27, 379-423 and 623-656.

24. The Environmental Impact Monitoring Center of the Ministry of Nature Protection of the Republic of Armenia on the Environmental Monitoring Results of the Environmental Impact Assessment. 2009. 55 p. (in Armenian). 